\title{
Carriego en la primera vanguardia histórica: las reescrituras de Olivari
}

\author{
2. Sara Amalia Bosoer / Universidad Nacional de La Plata / saraabosoer@hotmail.com
}

\section{Resumen}

Propongo un recorrido por diversos cuentos, novelas y poemas que Nicolás Olivari escribe entre I922 y 1929, para estudiar los envíos más o menos explícitos que realizan a los textos de Carriego. De este modo, se describe el lugar que la literatura de Carriego ocupa en la construcción de una tradición local y de qué modo posibilita un desplazamiento de lo que se pensaba como literatura en la década de 1920.

Palabras clave: vanguardia $\cdot$ Olivari $\cdot$ Carriego $•$ reescrituras $\cdot$ poesía argentina

\begin{abstract}
I propose a journey through different stories, novels and poems that Nicolás Olivari wrote between 1922 and 1929, to study the more or less explicit shipments to the Carriego texts. In this way, described the place as Carriego literature occupies in the construction of a local tradition and which mode enables a shift in the I920's.
\end{abstract}

Key words: avantgarde $\cdot$ Olivari $\cdot$ Carriego $\cdot$ rewrites $•$ argentinian

\section{Reescribir a Carriego: fundar una tradición}

Fecha de recepción: 2I/II/2OI4

Entre los escritores que Olivari cita, menciona y reescribe —explícita o veladamente- Carriego ocupa un lugar fundamental y único. En su escritura, al igual que sus compañeros de generación, aunque con diversas estrategias, Olivari encuentra un antecedente para establecer un linaje dentro de la literatura local. En este sentido, Carriego anticipa dos operaciones troncales del programa olivariano: la construcción de un territorio literario necesario para inscribirse y escribir una literatura argentina; y la institución de una palabra popular como palabra poética. A su vez, Carriego posibilita un repertorio de temas y procedimientos.

Beatriz Sarlo dijo que Carriego había definido en pleno apogeo del modernismo, en el que afilia parte de su obra, una temática urbana que permitió incluir al barrio en todas sus dimensiones dentro de los posibles temas literarios. Si el
Fecha de aceptación: 22/12/20I4 